\title{
Impact of Quality Circle Towards Employees \& Organization A CASE STUDY
}

\author{
${ }^{1}$ Mr. Rajesh Chaudhary, ${ }^{2} \mathrm{Mr}$. Lalit Yadav \\ ${ }^{I}$ (M. Tech IV Semester) Assistant Engineer 132 KV G.S.S. RVPNL, Hameergarh Distt. Bhilwara (Raj.) India. \\ ${ }^{2}$ Asstt. Professor, Department of Mechanical Engineering, Mewar University, Gangrar Distt. Chittorgarh (Raj.) \\ India
}

\begin{abstract}
This study is an attempt to focus on the impact of quality circle towards employees \& organization. Employee's attitude towards participative management is also discussed in detail through the case study. The observed data are analyzed through cause-effect diagram, Pareto-diagram etc. The results and findings are not only amazing but also beneficial to both employees \& organization. It results in - Drastic reduction in wastage, considerable increase in average saving, minimizing financial losses, and increased employee's motivation. By operating machine with care and minimizing wastage, the production \& hence productivity increases considerably. It also aims individual as well as group development by bringing out hidden capabilities of the employees, their change in attitude, skill development \& good team relationship. It enhanced the quality of the output \& services. Significance and perception of training with good leadership qualities are the success of quality circle in any organization. This study reveals \& suggests that the positive attitude will be developed. It leads to overall improvement in organizational culture as well as performance of employees.
\end{abstract}

Key words: Quality Circle, Participative management, Employee's motivation, Productivity, Group development, Hidden capabilities, Overall improvement, Organizational culture.

\section{INTRODUCTION}

In olden times Indian industries were practicing on older concept of system, to manage the scientific techniques. The disadvantages of which were barrier of mistrust, Individualism \& non involvement of employees in management of organization.

A quality circle is a volunteer group, composed of regular employees, who meet to discuss workplace improvement \& make presentation to management with their ideas especially relating to quality of output. It improves the performance of the organization, motivates \& enrich the work life of employees.

\section{PRINCIPLE -}

The basic principles behind quality circle activities are as follows-

- To contribute for improvement \& development of the organization.

- To exercise human capability fully and to explore hidden capabilities.

- To respect humanity \& build a worth while to live in happy positive environment.

\section{CONCEPT}

The modern concept has generated new ideas by involving task performer at the grass root level to the work of employees in organization.

It motivates the employees to follow new techniques at shop floor level by forming small groups \& sought their help in solving day to day problems encountered during the manufacturing \& production.

"The Person who is actually doing the job knows the job best." This is the basic guideline which introduces the modern concept of quality circle in an organization for the employees at grass root level \& has opportunity to perform effectively \& meshing well with the activities of the other level i.e total involvement of the employees \& their intellectuals. It results in tremendous change in working environment between employees \& management of organization.

The management approach of Q.C. for an organization is focused on quality, based on participation of all members and aiming at long term success through benefits to all the employees, organization and to the society as well 


\section{STRATEGIES -}

Every organization makes great effort, strictly for enhancing teamwork, organizational cultural building, empowering and involvement of employees, upliftment of employees through training \& sharing responsibilities etc. It also stresses on finding root cause \& taking corrective measures of the problem. The two major strategies are-

(i) Kaizen

(ii) 5 S Quality principles.

\subsection{KAIZEN -}

JAPANESE Meaning - $\quad$ "Change for better" or improvement.

ENGLISH Meaning - Continuous improvement.

It refers to work place quality. These strategies aim to eliminate wastage \& idling.

\subsection{S QUALITY PRINCIPLE -}

5 'S' are the basic foundations for implementing Quality Circle. The 5 'S' are as follows -

Sr. No. Japanese Term Equivalent 'S' For English Meaning

1. SERI Sort Disposal of unwanted.

2. SEITON Systemize Proper Layout.

3. SEISO Sweep Cleaning.

4. SEIKETSU Standardizing Standardize

5. SHIT SUKE Self Discipline Discipline through training.

\section{OBJECTIVES}

(a) To bring change in employee's attitude \& continuous improvement of employees and organization.

(b) Self development of employees by bringing out the hidden potential of individuals.

(c) Developing team spirit i.e Zero conflict among the employees and the management.

(d) Improved organization culture.

\section{FUNCTIONS}

a) It facilitates manufacturing process control.

b) Mutual and self development of employees in an organization.

c) Promotes the participation of the employees for improvement of the work place, along with the productivity.

\section{PROBLEM SOLVING TECHNIQUES}

The following are the basic techniques to identify, analyze \& solve work related problems.

(i) Brain storming

(ii) Collection of Data.

(iii) Cause - effect diagram.

(iv) Pareto analysis

(v) Cumulative line diagram.

\section{METHOD}

This study uses descriptive method. Report is being taken regarding what has happened and what is happening. The collected data are so arranged \& analyzed that they must fulfill the aim for the particular purpose. It includes the survey and fact finding enquiries of different kinds at various levels in the organization.

7.1 Sample Size: - For the purpose of survey, 25 employees were selected for sampling. The population elements are selected on the basis of the strength of particular unit.

7.2 Random sampling method: - In this study, probability sampling method is used which means each \& every item of the population has an equal or known chances of being selected.

7.3 Questionnaire: - These are most commonly used structural techniques for the purpose of data collection. It consists of a series of verbal or written questions to which respondent replies. The questionnaire are of two types-

(a) Open ended: - These are first questions and acceptance response is not provided to respondent.

(b) Close ended:- It is alternative question. The acceptance response is provided to respondent. 
7.4 Data Collection :- The data so collected are of two types :-

(a) Primary Data: - These are collected through method of questionnaire in which the details are collected from the respondent by filling up questionnaire.

(b) Secondary Data: - These are collected from website, company order etc.

VIII.

Identification of problem.

(ii) Selection of problem.

(iii) Analysis of problem.

(iv) Generate alternate solution.

(v) Selection of the best solution.

(vi) Prepare plan for action.

(vii) Presentation of solution to the management.

(viii) Implementation of the solution by management.

\section{OUTCOME}

The success of the impact of Quality Circle towards employees \& organization depends on -

- How well the members of the Quality Circle work \& integrate together.

- How well the circle philosophy has been evolved to fit into the company's style in an organization.

This study indicates the Quality Circle activities often appear to resume once employees condition have been stabilized.

The employees are interested in Quality Circle programme if their participation will be benefited to themselves as well as to the organization. They must be well trained in group dynamic and problem solving methods. Employees are benefited in terms of improved attitudes, moral, skills, knowledge \& communication. The organization is benefited in terms of improved quality \& quantity of output product and services, cost saving of material and financial gain, hence productivity.

\section{LIMITATIONS -}

1) Employees have limited power to solve any identified problem.

2) The involvement of employees is limited due to restriction or limited impact of Quality Circle on decision making procedure.

3) The impact of Quality Circle is not effective when its approach is much more participative management in an organization.

4) Self directed team work has no considerable impact for implementation of management approach of Quality Circle.

This study shows that Quality Circle has considerable impact towards positive attitude of employees and the concept is actively live \& effectively towards organization.

\section{CASE STUDY -}

Questionnaire were prepared and given to random selected employees of the company $\mathbf{M} / \mathbf{s}$. Sangam Spinners Ltd., Bhilwara. Response and findings from gathered information of questionnaire are as under :-

\section{(A) RESPONDENTS CLASSIFICATION BASED ON}

a) Gender:-80\% of the respondents are Male \& $20 \%$ of the respondents are Female.

b) Age:-28\% of the respondents belong to the age group of $41-45$ years, $16 \%$ of the respondents belong to the age group of 31 to 35 years. $16 \%$ of the respondents belong to the age group of above 45 years. $12 \%$ of the respondents belong to the age group of 36 to 40 years. $16 \%$ of the respondents belong to the age group of 26 to 30 years \& $12 \%$ of the respondents belong to the age group of 20 to 25 years.

c) Educational Qualification:- 32\% of the respondents have 10th as their educational qualification. $20 \%$ of respondents have Below 10th as their educational qualification. $12 \%$ of the respondents have 12 th as the ir educational qualification. $8 \%$ of the respondents have UG qualification. $8 \%$ of the respondents have ITI qualification. $8 \%$ of the respondents have Diploma qualification. $4 \%$ of the respondents have PG qualification, $4 \%$ of the respondents have B.E. qualification and $4 \%$ of the respondents have other qualifications.

d) Designation:- 51\% of the respondents are Labours, $18 \%$ of the respondents are Others designation, $12 \%$ of the respondents are Engineers, 9\% of the respondents are Technical Assistant / Helper, 6\% of the respondents are Operators \& $4 \%$ of the respondents are Supervisors. 
e) Experiences:- $63 \%$ of the respondents have the experience of above 5 years, $15 \%$ of the respondents have the experience between 4 to 5 years, $7 \%$ of the respondents have the experience between 2 to 3 years, $6 \%$ of the respondents have the experience of below 1 year, $5 \%$ of the respondent have the experience between 3 to 4 years \& $4 \%$ of the respondents have the experience between 1 to 2 years.

f) RESPONDENTS AWARENESS ABOUT QC

\begin{tabular}{|c|l|c|c|}
\hline S.No & Respondents Awareness about Quality Circle & $\begin{array}{c}\% \text { of Respondents } \\
\text { Accepted }\end{array}$ & $\begin{array}{c}\% \text { of Respondents } \\
\text { rejected }\end{array}$ \\
\hline 1 & All the QC projects are implemented & 84 & 16 \\
\hline 2 & QC Projects reduce the cost of functioning & 96 & 4 \\
\hline 3 & QC activities consume the production time & 80 & 20 \\
\hline
\end{tabular}

g) SCORE: EMPLOYEES ATTITUDE TOWARDS IMPACT OF QC\{BASED ON \% ANALYSIS\}

\begin{tabular}{|c|l|c|c|c|c|c|}
\hline & SA & A & N & DA & SDA \\
\hline 1 & Creative thinking skill & 56 & 44 & - & - & - \\
\hline 2 & Communication ability & 32 & 60 & 8 & - & - \\
\hline 3 & Decision making ability & 40 & 48 & 8 & 4 & - \\
\hline 4 & Interpersonal relationship & 36 & 56 & 4 & 4 & - \\
\hline 5 & Interest in team work & 48 & 44 & 8 & - & - \\
\hline 6 & Knowledge & 60 & 36 & 4 & - & - \\
\hline 7 & Leadership skills & 36 & 60 & 4 & - & - \\
\hline 8 & Problem solving ability & 48 & 44 & 8 & - & - \\
\hline 9 & Skill & 56 & 40 & 4 & - & - \\
\hline
\end{tabular}

h) SCORE: COMPARISION BETWEEN QC AND NON QC MEMBER \{BASED ON \% ANALYSIS\}

\begin{tabular}{|c|l|c|c|}
\hline S. NO. & \multicolumn{1}{|c|}{ FACTORS } & QCMEMBER(in \%) & NONQCMEMBER(in \%) \\
\hline 1 & Job satisfaction & 72 & 28 \\
\hline 2 & Willing to expand effort for achieving organization goal & 68 & 32 \\
\hline 3 & No Intention to quit & 80 & 20 \\
\hline
\end{tabular}

i) SCORE: MOTIVATIONAL FACTOR WHICH INFLUENCES EMPLOYEES \{BASED ON WEIGHTED ANALYSIS\}

\begin{tabular}{|c|l|c|c|c|c|c|}
\hline S.No. & \multicolumn{1}{|c|}{ FACTORS } & SA & A & N & DA & SDA \\
\hline 1 & Attending various organizational programmes & & $\checkmark$ & & & \\
\hline 2 & Colleagues encouragement & & $\checkmark$ & & & \\
\hline 3 & Learning new techniques & & $\checkmark$ & & & \\
\hline 4 & Management's encouragement & $\checkmark$ & & & & \\
\hline 5 & Participating in various competition & & $\checkmark$ & & & \\
\hline 6 & Positive change of QC members & & $\checkmark$ & & & \\
\hline 7 & QC's achievements & & $\checkmark$ & & & \\
\hline 8 & Rewards and awards & $\checkmark$ & & & & \\
\hline 9 & Subordinates involvement & & $\checkmark$ & & & \\
\hline 10 & Superior's motivation & & $\checkmark$ & & & \\
\hline
\end{tabular}

(SA- Strongly agree, A-Agree, N- No opinion, DA- Disagree, SDA- Strongly disagree)

(B) This study was conducted at M/s. Sangam Spinners Ltd. Bhilwara, where 30 ring frames machines are working in Unit No.1.

Production Problem:- There is a major problem of idling of ring frame machines. It results in $4 \%$ lower production and considerable financial loss. There are 20 ring frame machines having 576 spindles in each machine. Each spindle contains 2440 yard yarn per bobbin. The quality of yarn is 24 counts. Idling of machine results in loss of $0.06 \mathrm{~kg}$. of yarn per bobbin which amounts to loss of Rs. 3500.00 per annum per bobbin.

\section{Causes of Idling of Ring Frame Machine: -}

(i) Bad working condition due to Ambient Temperature \& relative humidity.

(ii) Defective Roving. 
(iii) Displacement of spindle tapes because of misalignment \& jamming of pulley.

(iv) Fiber blends not suited to Spinning system.

(v) Design of machine creel not suitable.

(vi) Use of Non Standard machine accessories (Spares, Ring Travelers, Aprons etc.)

(vii) Shortage of back stuff.

(viii) Reluctance of piecers to re-start spindle machine \& fitters to attend idle spindle machine.

Cause- Effect Diagram \& Pareto chart for above problems are described as under-

The major reasons for less production are as under-
(a) Bad working conditions.
(b) Blending problem of fiber.
(c) Creel design problem.
(d) Displacement of tape.
(e) Defective simplex roving.
(f) Problem with accessories.
(g) Problem with personnel.
(h) Shortage of Back Stuff.

The above problems are explained with cause-effect Diagram in Figure as shown:-
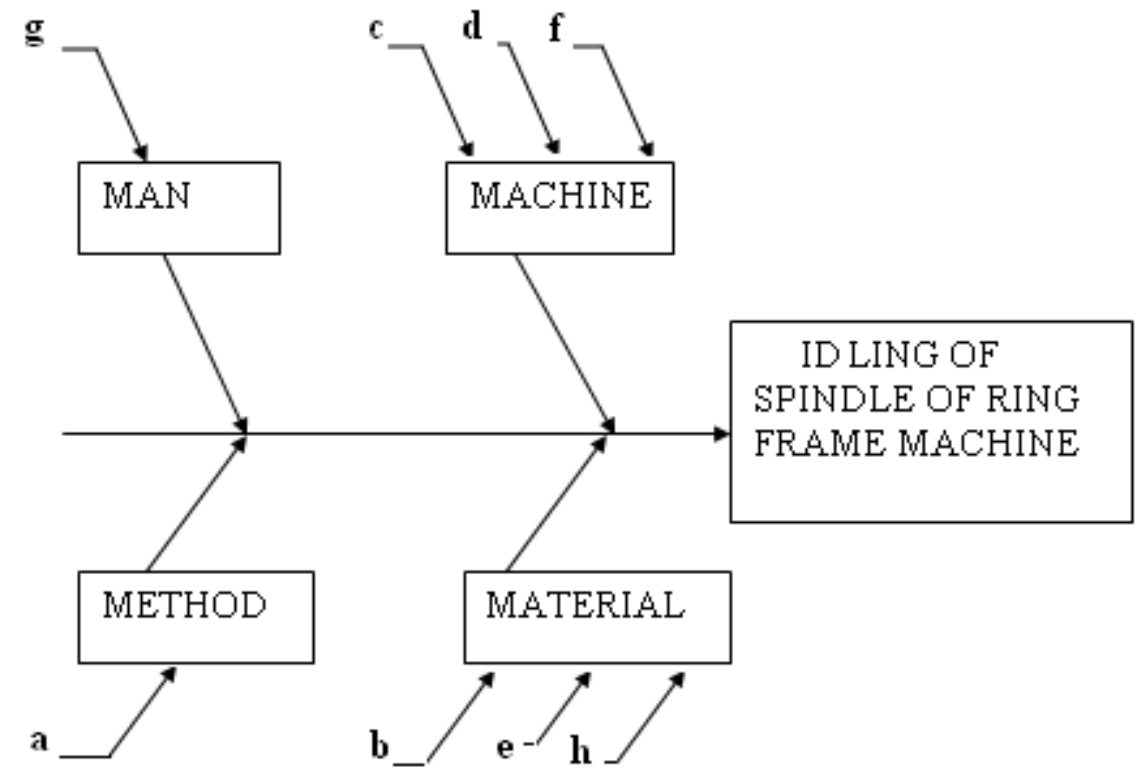

FIG: CAUSE-EFFECT DIAGRAM

Here, the two major problems are -

1. With Machine- Like Blending of fibers, defective simplex roving \& shortage of back stuff.

2. With Material- Like creel design, displacement of taps \& problem with accessories

If the above two problems are controlled, the problem will be shorted out by more than $75 \%$.

The rest of the problems are related to -

(1) Man

(2) Method.

Which can be easily controlled with proper co-ordination \& training. 


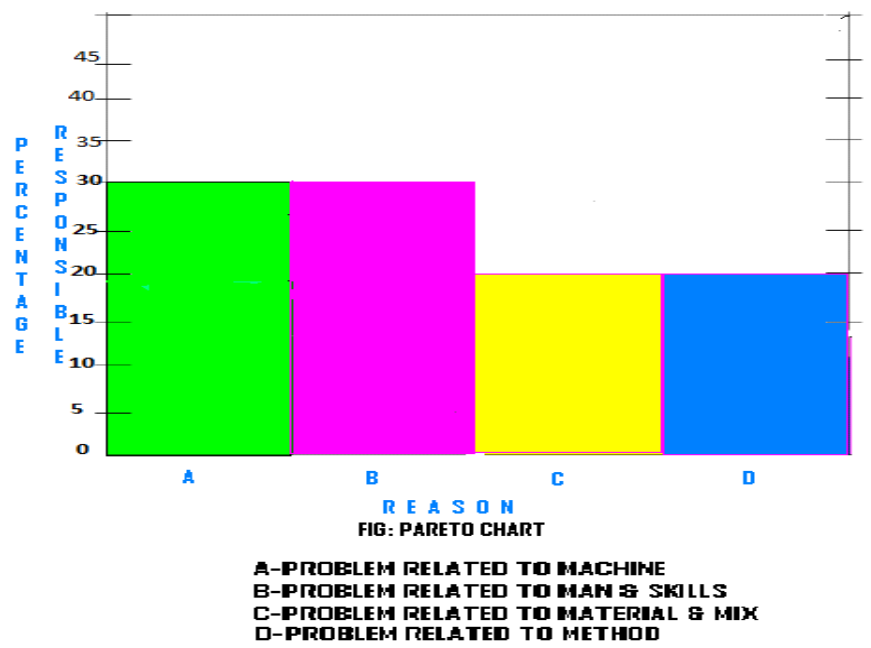

Pereto chart is shown in figure. It shows that there is a problem regarding the method \& associated improvement. This problem accounts for $20 \%$. There is also problem regarding material \& material mix i.e. different proportion of fiber are not being mixed properly. This problem is responsible for another $20 \%$. Problem with machine is responsible for $30 \%$ \& manpower problem contributes for another $30 \%$.

After analysis of the problem in details, the following suggestions were given by the quality circles :-

(1) Prevent the production of defective simplex roving \& control.

(2) Whenever back stuff shortage problem is noticed, adopt the practice of cutting the Rigs.

(3) Ensure timely replacement of accessories and use standard accessories.

(4) Training to machine cleaner \& tap man for correct work practice.

(5) Suitable techniques should be adopted for motivation of employees \& workers.

(6) Standardization of fiber blend should be done for suitable system.

Implementation of suggestions in different phases are as follows-

(a) The training programme should be scheduled for all types of employees.

(b) Standard accessories \& spare parts were procured.

(c) Working condition - Relative humidity and temperature should be controlled by additional equipments.

(d) The quality of simplex roving is to be improved.

(e) Advance planning of spindle utilization should be ensured.

(f) Motivational plan for employees and workers are to be framed and should be implemented.

(g) One additional row of creeling pegs installed on either side of ring frame machine to avoid bobbins to feed raising to all spindles.

\section{Results \& Analysis:} observed.

After implementation of above suggestions, considerable improvement in ring frame production was

(a)The details of cost-benefit analysis is as under:-

The profitability on sale/ produce under booking from $4 \%$ to $2 \%$.

(1) Before quality circle, sale/ produce under booking :- $4 \%$.

(2) After implementation of Quality Circle \& Suggestions - the sale/ produce under booking :- $2 \%$.

(3) Thus the gain in total production is $\quad:-2 \%$

Considering the average production per day $\quad 70000 \mathrm{~kg}$

Gain in production $2 \%$

$1400 \mathrm{~kg}$

Taking the contribution Rate/kg - $\quad$ Rs. $\quad 40.00$

Gain per day $1400 \times 40=\quad$ Rs. 56000.00

Gain per month $56000 \times 30=\quad$ Rs. 1680000.00

Gain per annum $=1680000 \times 12=\quad$ Rs. 22160000

The outcome benefit from implementation of Quality Circle towards organization is Rs. 22.16 million/annum.

(b) The attitude of employees and workers became more positive.

(c) The morale of employees and workers were boosted.

(d) Job satisfaction is achieved by employees and workers. 


\section{CONCLUSION}

The impact of Quality circle towards employees and organization has become very important for improving a firm's process capabilities in order to achieve fit and sustain competitive advantages.

It focuses on encouraging a continuous flow of incremental improvements from the bottom of the organizations. Autonomy and complexity are the other two attitudes enhanced through company's implementation. Job satisfaction and company commitment are the work attitudes, being the dimensions of employee attitudes. Quality circle can be linked more with productivity which cannot be measured only by money.

There are various factors involved in developing the employees attitude towards quality circle. The organization plays a facilitator role in developing Quality circle. The transparency and integrity of the organization is very much important for the smooth functioning of quality circles. The culture has great impact on the quality circles based on employee involvement, employee empowerment, perceived organizational support \& employee engagement.

The success of the quality circle movement in the SANGAM SPINNERS LTD, BHILWARA is definitely a collective effort and involvement of both the management and employees. Hence it is evident that Quality circles are the important tools for achieving total quality and organizational culture.

\section{References}

[1] Tait, M., Padgett, M. Y., \& Baldwin, T. T. (1989). Job and life satisfaction: A reevaluation of the strength of the relationship and gender effects as a function of the date of the study. Journal of Applied Psychology, 74, 502-507.

[2] Newbury Park, CA: Sage. Hofstede, G. (1985). The interaction between national and organizational value systems. Journal of Management Studies, 22, 347-357.

[3] Saari, L. M. (2000). Employee surveys and attitudes across cultures. In Business as unusulEmployee Attitudes and Job Satisfaction 407 .

[4] Mirvis, P. H., \& Lawler, E. E. (1977). Measuring the financial impact of employee attitudes. Journal of Applied Psychology, 62, 1-8.

[5] Smith, P. C., Kendall, L. M., \& Hulin, C. L. (1969). The measurement of satisfaction in work and retirement. Chicago: Rand McNally.

[6] Brayfield, A. H., \& Rothe, H. F. (1951). An index of job satisfaction. Journal of Applied Psychology, 35, 307

[7] Macey, W. H. (1996). Dealing with the data: Collection, processing, and analysis. In A. I. Kraut(Ed.), Organizational surveys: Tools for assessment and change (pp. 204-232).

[8] Robert E. Stevens, Robert L. Moore. (1981). Determination of significant factors for success and a general model for implementing a quality circle process.

[9] Steel R.P. \& Shane G.S. Research on QC technical and analytical implication (1986)

[10] Turban E Do QC pay training and development J.39 (1985) 10-12

[11] Smith P.Andrews N \& Trikha R. Managing QC in an Org. Co. communication (1991)

[12] Hill F M, Study of performance related outcome of QC participation (1993) 28-42

[13] Tang T.L.P \& Butler E. Attribution of QC problem solving, personnel, mgt (1997) 203

[14] Marks M.L.Hackett E.J employee participation in QC programme, impact on quality of work life, productivity, J applied Psychology 71(1986) 61-70

[15] Metz E. J. QC ahead Training \& Devpt J,35 (1981)108-112 